\title{
MULTICULTURAL COMPETENCE AND PERFORMANCE OF GOVERNMENT APPARATUS: THE EMPIRICAL STUDY IN LAMPUNG PROVINCE
}

\author{
Suyanto $^{1^{*}}$, Nedi Hendri ${ }^{1}$ \\ ${ }^{1}$ Muhammadiyah University of Metro, Metro, Indonesia \\ * Corresponding Author: yanto.metro@gmail.com
}

\begin{abstract}
This study was Carried out to analyze the effects of multicultural competence models consisting of understanding, attitude and individual skill on the performance of government apparatus. The study applied a survey method with the survey subject of regent and municipal Civil Servants of Lampung Province. Samples determination was based on a purposive sampling technique. The study collected 127 respondents. Analysis on the Data used a Structural Equation Model (SEM) operated under AMOS application program. This empirical result proved a direct effect on understanding between attitude; attitude on skills; and skills on the performance of the government apparatus. The Study Also Showed an attitude and skills as mediation between understanding the indirect effect on the performance of the government apparatus. However, the direct effect on understanding between skills and attitudes on performance was insignificant. Finally, this result implies that multicultural understanding alone is not sufficient to Determine the performance of government apparatus, but it takes attitude and skills to respond in different cultural Contexts. Reviews these results might be used to develop a unified theory effects on multicultural competence.
\end{abstract}

Keywords: competence, multicultural, performance.

\section{INTRODUCTION}

Culture is one of the topics that interest researchers from diverse disciplines. This is because the culture has a definition that are constantly evolving, it is characterized by the presence of the defining cultural phenomenon that never ends. For example, Matsumoto (in Dayakisni \& Yuniardi, 2003) defines culture as a system ranging from attitudes, values, beliefs, and behaviors that are owned by a group of people. While Ralph Linton (2001) more emphasis on the inherited habits of the members of a particular community.

In addition, the culture as one of the external factors that affect a person's behavior (Maheswaran \& Shavitt, 2000). Some studies, such as the Lewin (2002) found that employee behavior is a function of the interaction between the personal characteristics of the surrounding environment. Containing social cultural environment that affects the work that can be called work culture. Armstrong (2000) states that the values itself is one of the characteristics possessed by someone. This means that culture affects the behavior or attitude of a person who carries through the values it carries through the surrounding neighborhood. With that understanding, the different cultural perceptions will determine the attitude and behavior of different and influential as in personal responsibility, attitude towards authority and the law, the use of time, to respect the rules, and fair treatment. Such issues have such an important role in fostering working relationships and the achievement of better performance.

Lampung province is one of the first immigrants. Most of the people come from the island of Java, such as Semarang, Yogyakarta, Banyumas, Tegal, East Java, and some came from the island of Bali. As one of the objectives of immigrants, each community in Lampung province has a regional language, habits, customs and different cultures. This distinction has often give rise to serious problems, namely disputes and wars between tribes/ethnic groups. In fact, the socio-cultural differences is often carried in the local government work. If it happens continuously, not only interfere with work, but also impact on the performance of government apparatus in Lampung province.

Multi empirical consequences of social dynamics caused by the different cultures, it is necessary not only an awareness of the difference, but the multicultural competence of government apparatus to be able to understand and respond to the behavior and attitudes in the different cultural contexts. Reflected their multicultural competence in the understanding and attitudes of local government apparatus in Lampung province will be a strength and not a bottleneck in improving the performance of government apparatus in the working environment. However, as long as there has been no research done in an integrated manner to identify the model of multicultural competence in relation to the performance of apparatus in local government. 
Multicultural competence is the ability to understand the identity and values of various cultures (culture) adopted by itself and how the identity and values that affect perceptions of the other people who come from different cultures (McAllister \& Irvine, 2000). Someone who has a high multicultural competence are marked with an understanding of empathy (capable to feel feelings of others). He was able to understand and accept others who are different in feel, think, interact, behave and in how to take a different decision with him. Thus the multicultural competence consists of three elements, understanding, attitudes and skills. The meaning of understanding is aware of the differences among themselves to others. Attitudes are evaluative statements about other cultures and how people respond to the differences that occur between their own cultures with other cultures. While skill is the ability to actualize their understanding and attitudes in the context of intercultural differences in the form of real behavior.

Research on the model of the influence of multicultural competence is intended to provide empirical evidence about whether and how the apparatus comprising multicultural competency of understanding, attitudes and skills will affect the performance of government apparatus in Lampung province. Thus the results of this study are expected to be useful in the development of the theory of management control and provide a practical contribution to the local government in multicultural management apparatus owned as property or asset for the organization of local governments.

\section{Figure 1. Model of multicultural competence effect on performance}

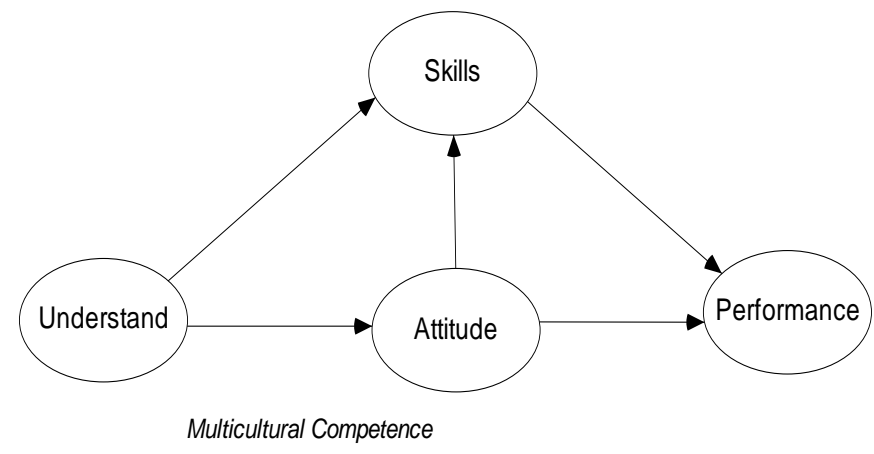

Figure 1 above is a conceptual model underlying this research. The images show that the multicultural competencies include understanding, attitudes and skills of personnel in responding to their tribe and ethnicity differences in Lampung province. There are two possibilities to produce a good performance. Firstly understanding of personnel directly effect the attitude which then effect the performance; and Both their actualization in the form of individual skill as intervening effect the understanding and attitudes towards the performance of government apparatus in the province of Lampung.

\section{HYPOTHESES DEVELOPMENT}

\subsection{The Influence Of Multicultural Understanding On The Attitudes And Performance}

Lampung province have cultural diversity very much. Cultural diversity should be viewed as a strength and wealth areas that need to be maintained and preserved its existence, so that the necessary common understanding on mutual respect and cooperation to realize a multicultural society. Comprehension is a process or way of studying carefully about multicultural order to understand. Someone who has an understanding of something that will generate a good attitude is also about it. Robbin (2006) explains that attitude is a function of references.

From these explanations, suggesting that if government officials have a good understanding of the different cultures (multicultural) then the good and positive in their wellbeing. The attitude of the apparatus address in the form of mutually aware of the differences, respect, and will avoid attitudes that can cause problems in the workplace. Based on these arguments it put forward the research hypothesis as follows:

H1: Understanding multicultural affect on the attitude of the government apparatus.

Attitude is an important determinant of behavior, because attitudes and personalities associated with the perception that would motivate a person to perform an action. Attitude is defined as a mental readiness, studied and organized through understanding and experience. Thus, the attitude has a certain influence on how responsive person against another person, and circumstances related thereto. Gibson (1988) explains that the attitude is always associated with the emotional component, cognitive component (perceptions, opinions, beliefs) and behavior. This means that the apparatus will conduct the works well when all three components in accordance with personality. 
Additionally, Basadur (1982) in Williams (2004) suggested that one believed to be linked to the performance of the organization is one of attitude. It is based on the premise that understanding to improve the ability to be better so it will affect the individual's performance. On the basis of these hypotheses can be formulated as follows:

$\mathrm{H} 2$ : The attitude of the government apparatus affect on the performance.

Based on the description of the underlying $\mathrm{H} 1$ and $\mathrm{H} 2$ above shows the influence of multicultural understanding of the performance indirectly through attitude apparatus. Therefore obtained the following hypotheses:

H3: Understanding multicultural indirect effect on the performance through the attitude of the government apparatus.

\subsection{The Influence Of Multicultural Understanding On The Individual Skill And Performance}

Multicultural competence is reflected in the knowledge, attitudes and skills of government apparatus in addressing the different cultures. The understanding will make him aware of the culture. Someone who has a good understanding of the culture then communicate well and flexibly adapt. This attitude includes an attitude of respect and underlying desire to learn, improve and develop to be able to manage it better. While skills as the capacity needed to implement the result of understanding and attitude required connected different cultures.

Their multicultural understanding will be a force in improving the performance of government officials in the working environment. Nevertheless, multicultural understanding alone is not sufficient as factor determinant of performance but necessary skills on how they actualize themselves in a work environment. Based on the above research hypotheses obtained as follows:

H4: Understanding multicultural effect on the individual skills of government apparatus.

H5: Individual skill affect on the performance of government apparatus.

Based on the description of the underlying H4 and H5 above shows the influence of multicultural understanding of the performance of indirectly through the apparatus skills. Therefore obtained hypothesis that:

H6: Understanding multicultural indirect effect on the performance of government apparatus through individual skills.

\subsection{The Influence Of The Apparatus Attitude On Individual Skill}

The apparatus attitude of the multicultural, one of which is reflected in the attitude of tolerance. Tolerance attitude contrasts with the attitude of ethnocentrism despised other cultures. Thus, tolerance demonstrate the breadth of one's mindset as well as showing its understanding of the conditions that followed the organization's culture. Meanwhile, individual skills the capacity to implement the results of the understanding and attitudes in organizations that have a different culture. The higher level of multi-cultural dynamics, the higher the individual skills needed in the organization. This is because the demand environment for mutual respect and tolerance between one apparatus to another.

Based on the above concluded that tolerance, mutual respect, cooperation, and other attitude is basically the embodiment of the level of their understanding of multicultural, and ultimately affect the attitude of the individual skills they have. Thus the proposed hypothesis that:

H7: Attitude of government apparatus affect on the individual skills.

\section{RESEARCH METHOD}

\subsection{Design And Sample}

Study on the influence of multicultural competence on the performance of government apparatus is a research carried out in cross section and are categorized as quantitative research. Data analysis techniques used in this study is Structural Equation Modeling (SEM). To support the use of data analysis software help AMOS version 16.0. Estimation of structural equation model was analyzed with full model to look at the suitability of the model and causality built into the model. The suitability of the model evaluated based on the criteria as recommended goodnessof-fit model.

The study population includes employees of government apparatus in the province of Lampung. Although the province of Lampung is composed of various counties and cities, but in general its characteristics almost the same as it has the same community heterogeneity. Determination of the sample using purposive-sampling. According Sudjana (2005) purposive sampling method is a method of sampling to certain considerations. On the basis of the sample selected employees of the apparatus in three counties and municipalities, namely East Lampung District, Central Lampung District and Metro City. Of all samples were selected, divided into three parts, namely lampung culture, java culture, and bali culture. 


\subsection{Data Collection}

This research uses data in the form of primary data and secondary data. Collecting primary data through questionnaires and in-depth interviews (depth interview). Research questionnaire is delivered and picked up directly by the researcher to 135 respondents. The rate of return of questionnaires (respond rate) of $94 \%$ or 127 respondents. While the interview is intended to gather data on the values of cultural and multicultural competence of government apparatus in the province of Lampung in more depth.

In addition to the primary data, this study also uses secondary data obtained from the publications, both from government agencies, books, journals and internet sites. Thus, the method of data collection is varied using several techniques, depending on the desired data and data types.

\section{RESULT}

\subsection{Descriptive Statistics}

Summary descriptive statistics of each variable of this study are presented below:

Table 1.

Summery of Descriptive Statistics ${ }^{\mathrm{a}}$

\begin{tabular}{lrrrrr}
\hline & N & Minimum & Maximum & Mean & $\begin{array}{c}\text { Std. } \\
\text { deviation }\end{array}$ \\
\hline Unders & 127 & 8 & 19 & 13,17 & 2,407 \\
Attitude & 127 & 7 & 20 & 12,91 & 2,320 \\
Skills & 127 & 20 & 40 & 29,99 & 3,421 \\
Perform & 127 & 9 & 20 & 14,29 & 2,215 \\
Valid N (listwise) & 127 & & & & \\
\hline
\end{tabular}

${ }^{a}$ Reprinted from the output AMOS version 16.0

Based on table 1, the variable has a multicultural understanding of the actual value range between 8 to 19 , the average value of 13.17 and a standard deviation of 2.407. Thus, the average actual value is above the average theoretical value $(13.17>12)$. These results indicate that respondents understand what is at the level of good multicultural. While the attitude variables have the actual value ranges between 7 to 20, the average value of 12.91 and a standard deviation of 2.320. Thus, the actual average value was slightly above the average theoretical value $(12.91>12)$. These results indicate that respondents to the multicultural attitude of government apparatus in the Lampung province is at a medium level.

Individual variables have the skills actual value ranges between 20 to 40, the average value of 29.99 and a standard deviation of 3.421. Thus, the average rat actual value is above the average theoretical value $(29.99>24)$. These results indicate that respondents regarding multicultural skills of government apparatus in the Lampung province on a good level.

Variable apparatus has a performance range of the actual value ranging from 9 to 20, the average value of 14.29 and a standard deviation of 2.215. Thus, the average rat actual value is above the average theoretical value (14.29>12). These results indicate that the apparatus performance in Lampung province is at the level very good.

\subsection{Model Fit Assessment}

According Hair et.al (in Ferdinand; 2006) analysis of Structural Equation Model (SEM) no single statistical test equipment to measure or testing the hypothesis about the model. The statement was sufficient to provide evidence that there are different types of fit index that can be used to measure the degree of conformity of whether a model can be accepted or not.

Figure 2 is a construct of full structural equation model after conducting confirmatory factor analysis of each construct. Assessment model fit was done by comparing the results of testing against the criteria of goodness of fit indices full structural models.

The test results fit structural equation model of generating value for Chi-Square 82.039 with probability $\mathrm{p}=0.031$, $\mathrm{CMIN} / \mathrm{DF}=60$ and $\mathrm{AGFI}=0.678$. According to Ferdinand (2006) recommended value is $\mathrm{p}>0.05, \mathrm{DF} \leq 2,00$ and $\mathrm{AGFI} \geq 0,90$ means to be under recommended that indicates that the model has been accepted at a marginal level. While the value of GFI $=0.912$, and TLI $=0.917$ as recommended that the proposed model is accepted at the level of fit. Ghozali (2008) states that the Chi-square value is very sensitive to sample size, so there is a tendency Chi-square value will always be significant. Therefore it is advisable to ignore it and look more fit goodness. 
Figure 2. Structural Equation Model (SEM)

Multicultural competence and the performance of government apparatus

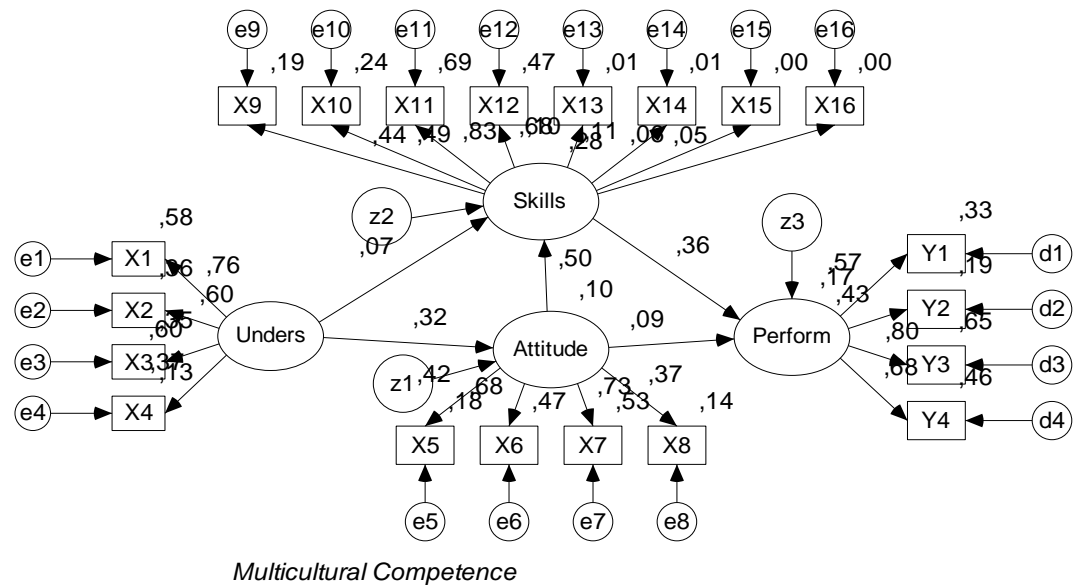

\subsection{Hypothesis Testing}

Output research hypothesis testing using AMOS program in the form of output regression weights are shown in Table 2. While the output of the relationship between exogenous variables on endogenous variables can be seen from the estimate standardized regression weights are shown Table 3. Criteria for hypothesis testing by Ghozali (2008) are as follows:

a. $\mathrm{CR}$ (critical ratio) $\geq 1.96$ significance level $\leq 0.05$ it means the exogenous variables affect the endogenous variables.

b. CR (critical ratio) $<1.96$ significance level $>0.05$ it means the exogenous variables did not affect the endogenous variables.

Table 2.

Regression Weights ${ }^{\mathrm{a}}$

\begin{tabular}{lclrcrc}
\hline & & \multicolumn{1}{c}{ Estimate } & SE & \multicolumn{1}{c}{ CR } & P \\
\hline Attitude & $<---$ & Unders &, 142 &, 071 & 1,998 &, 046 \\
Skills & $<--$ & Unders &, 035 &, 064 &, 539 &, 590 \\
Skills & $<---$ & Attitude &, 583 &, 242 & 2.415 &, 016 \\
Perform & $<---$ & Skills &, 598 &, 274 & 2,185 &, 029 \\
Perform & $<---$ & Attitude &, 176 &, 303 &, 582 &, 561 \\
\hline \multicolumn{5}{c}{${ }^{a}$ Reprinted from the output AMOS version 16.0} \\
\hline \multicolumn{7}{c}{}
\end{tabular}

Table 3.

Standardized Regression Weights ${ }^{\mathrm{a}}$

\begin{tabular}{lrlr}
\hline & & & Estimate \\
\hline Attitude & $<---$ & Unders &, 324 \\
Skills & $<--$ & Unders &, 068 \\
Skills & $<---$ & Attitude &, 502 \\
Perform & $<---$ & Skills &, 362 \\
Perform & $<---$ & Attitude &, 092 \\
\hline${ }^{a}$ Reprinted from the & output AMOS version 16.0
\end{tabular}

\subsection{The Direct Effect Of The Apparatus Multicultural Understanding (H1 And H4)}

$\mathrm{H} 1$ states that the understanding of multicultural influence on the attitude of the government apparatus. The result of estimation parameters (standardized regression weight) between two variables shows the influence of 0.324 and the value of the critical ratio $(\mathrm{CR})$ of 1.998 with a p-value $0.046(\mathrm{p}<0.05)$. The results of this study indicate that the understanding of multicultural influence on the attitude of the government apparatus, thereby H1 accepted.

H4 states that multicultural understanding affect the skills of government apparatus. The result of estimation parameters (standardized regression weight) between two variables shows the influence of 0.068 and the value of the 
critical ratio (CR) of 0.539 with a p-value $0.590(\mathrm{p}>0.05)$. These results suggest that multicultural understanding no effect on the skills of government apparatus, thus $\mathrm{H} 4$ unacceptable.

\subsection{Multicultural Influence The Attitudes And Skills Of Government Apparatus (H2, H5 And H7)}

$\mathrm{H} 2$ states that the attitude of the apparatus with the multicultural influence on performance. The result of estimation parameters (standardized regression weight) between two variables indicated the presence of 0.092 and the value of the critical ratio (CR) of 0.582 with a p-value $0.561(\mathrm{p}>0.05)$. The results of this study showed that the apparatus with their multicultural attitude does not affect the performance, thus $\mathrm{H} 3$ unacceptable.

H5 states that the individual skills affect the performance of the government apparatus. The result of estimation parameters (standardized regression weight) between two variables shows the influence of 0.362 and the value of the critical ratio (CR) of 2.185 with a p-value 0.029 ( $>>0.05$ ). These results indicate that individual skill affect the performance of government officials, thus $\mathrm{H} 5$ received.

H7 stated that the attitude of government officials regarding the multicultural influence on individual skills. The result of estimation parameters (standardized regression weight) between two variables shows the influence of 0.502 and the value of the critical ratio (CR) of 2.415 with a p-value of $0.016(\mathrm{p}>0.05)$. These results indicate that the attitude of the apparatus with the multicultural influence on individual skills, thus $\mathrm{H} 7$ received.

\subsection{The Indirect Effect Of The Apparatus Multicultural Understanding (H3 And H6)}

The test results do not directly influence knowledge, attitudes and skills on the performance of government apparatus in Lampung province can be seen in this table:

Table 4.

Standardized Indirect Effects

\begin{tabular}{|c|c|c|c|c|c|}
\hline \multicolumn{4}{|c|}{ Variable path } & \multicolumn{2}{|c|}{ Indirect effect } \\
\hline Perform <--- & Attitude & $<---$ Unders & & $0,324 \times 0,274$ & 0,088 \\
\hline Perform <--- & Skills & $<---$ Unders & & $0,231 \times 0,362$ & 0,083 \\
\hline Perform <--- & $\begin{array}{l}\text { Skills } \\
\text { Total Ind }\end{array}$ & $\begin{array}{l}<--- \text { Attitude } \\
\text { irect Effects }\end{array}$ & $<---$ Unders & $0,324 \times 0,502 \times 0,362$ & $\begin{array}{l}0,059 \\
0,230\end{array}$ \\
\hline
\end{tabular}

Table 5.

Standardized Total Effects ${ }^{\text {a }}$

\begin{tabular}{lrrrr}
\hline & Unders & Attitude & Skills & Perform \\
\hline Attitude &, 324 &, 000 &, 000 &, 000 \\
Skills &, 231 &, 502 &, 000 &, 000 \\
Perform &, 113 &, 274 &, 362 &, 000 \\
\hline \multicolumn{4}{c}{${ }^{a}$ Reprinted from the output AMOS version 16.0 }
\end{tabular}

H3 states that multicultural understanding indirect effect on performance through the attitude of the government apparatus. Based on Table 3, the magnitude of the indirect effect is 0.088 while the influence of a total of 0,113 (table 3). This study proves that multicultural understanding indirect effect on performance through the attitude of the government apparatus. Thus the attitude of the apparatus is quite mediate between these two variables or H3 acceptable.

H6 states that multicultural understanding indirect effect on performance through the skill of the government apparatus. Based on Table 3, the magnitude of the indirect effect is 0.083 while the influence of a total of 0,113 (table 3). This study proves that multicultural understanding indirect effect on performance through the skill of the government apparatus. Thus the apparatus sufficient skill mediate between these two variables so that H6 is acceptable.

\section{DISCUSSION}

Performance is the result of the quality and quantity of work accomplished by an employee in performing its functions in accordance with the responsibilities given to him. According to Rifai and Basri (2005) performance is essentially determined by three factors, namely the desire, individual skills and the environment. Therefore, to have a good performance, one must have a high desire, individual skills and a good environment for doing his job. Organizations that have a multicultural dynamics characterized by the language, rules and social values are different. Therefore, employees are required to know the language and culture of other people's behavior, knowing the principles of intercultural communication and practice it in communicating with others, The desire to know the culture of others, 
andindividual skills to interact is needed in carrying out the work in a heterogeneous organization. Without these two factors (individual wishes and skill), an organization will be very difficult to create a good working environment. Noting this, the multicultural competence becomes an integral part in producing a better performance.

Kotter and Heskett (1992) stated that cultural factors are shared values by individual and group behavior tend to be formed, so that the culture can be positive and negative forces in achieving effective performance. Gumilang (2015) mentions that cultural understanding is one dimension that is important to be owned by an employee in the context of cultural diversity (multicultural). This dimension includes the understanding and awareness that its cultural factors (race, gender, values, social class, etc.) will affect the development of themselves and their attitudes towards others. Therefore, every employee needs to know that its values and behaviors will affect the others. The study's findings reinforce Gumilang statement (2015) above, that the understanding of multicultural owned by the government apparatus influence on their positive attitude in the workplace. Influence between the two variables is quite large at 0.324 (Table 3).

In addition, make him conscious understanding of the culture. Someone who has a good understanding of the culture then communicate better and adapt flexibly. Furthermore, skills are necessary capacity to implement the result of understanding and attitudes required in different cultural contexts. On this basis, it is predicted that the understanding of multicultural influence on the skill of the government apparatus. However, this study cannot support the above statement. This study concluded that multicultural understanding not significantly affect the skills of government officials. This means that a high understanding of the multicultural apparatus, it cannot determine a good skill. This is due to that to improve the skills neededlonger process through education, training and experience. So understanding alone is not sufficient to affect changes in government personnel skills, especially in Lampung,

Attitude is an important determinant of behavior, because of the attitude associated with perception, personality, and motivation. Therefore, the attitude is defined as a mental readiness, studied and organized through understanding and experience. While skill isskill or skills possessed by a person in relation to others who have the culture and customs are different.Moreover, Gibson, et al. (1996) describes the skills or skill is competency-related tasks, such as the skills to operate a computer, with clear communication skills, people skills and adapt to other people for a specific purpose, and others. This study found that the attitude of the apparatus affects the very large individual skills are 0.502 and the subsequent effect on the performance of which is 0.362 (Table 3). These results indicate that an employee who is able to show a positive attitude about the multicultural will increase the skill for themselves, and ultimately affect the performance.

In some theories of human resources (such as: Robbin, 2006; Sunyoto, 2012), explains that the employee has a variety of attitudes and behavior in carrying out its role in an organization. Between employees against each other is not the same to appreciate their attitude towards different cultures. Culture brought by each employee affects the employee in the act. This attitude shows a positive or negative evaluation of a person about the various cultures that exist in their work environment. If employees face a problem in the workplace, either by colleagues or superiors then the situation can lead to a decrease in employee performance. And vice versa, if the employee is able to adapt to a variety of cultures that exist in the work environment will improve their performance. But the results of this study cannot prove there is significant between attitudes toward the performance of government officials in the province of Lampung. The influence of these variables is relatively small, namely 0.092 (Table 3). These results indicate that multicultural attitude owned by an employee does not directly influence the performance, but there are other factors that must be considered, such as individual skills.

The results of this study support the idea Rifai and Basri (2005) which describes the factordesires, individual skill and environmental factors that influence performance,Skill related to the technical ability or the practice of a thing that has been understood and learned. Based on descriptive statistics (Table 1) shows that the skills of government apparatus in the province of Lampung is at a good level. Individual skills are good in multi-cultural can create a good working environment as well, and ultimately improve performance. Thus, an understanding of multicultural indirect effect on the performance of individual skills possessed by employees or government apparatus. The indirect effect through individual skill by 0,083 of the total indirect effect of 0.230 (Table 4 ) and the rest through another variable is the attitude of the apparatus.

Although this study is able to provide some support for the hypothesis, but there are some disadvantages of the issue relatively short study duration and predominantly by mail questionnaire (survey research). Although the survey method simply provide much convenience and allows researchers obtained many respondents, the study will come experiments should be done in order to have the flexibility to precisely manipulate the desired researchers variables. Regardless of these limitations, this study provides empirical evidence that is essential for the development of a unified theory of how the multicultural competence effect on the performance of government apparatus. Finally, these results 
imply that multicultural understanding will affect the attitude, the next influential on the performance of individual skill.

\section{REFERENCES}

Armstrong., J. Taylor. 2000. Regional Economics and Policy. Third Edition. Oxford: Blackwell Publishing.

Bahrun A., Jensen CR. 2002. Drought-induced changes in xylem pH, ionic composition, and ABA concentration act as early signals in field-grown maize (Zea mays L). Journal of Experimental Botany.

Chariri, Anis. 2006. The Dynamics of International Financial Reporting Practice in Indonesian An Insurance Company: A Reflection of Javanese Views on an Ethical Social Relationship. Unpublished PhD thesis in Accounting, University of Wollongong, Australia.

Dayakisni T. \& Yuniardi, Salis. 2003. Cross-Cultural Psychology. Poor. UMM Press.

Ferdinand, Augusty. 2006. Structural Equation Modeling in Management Research. 4. Edition Publishers Agency Diponegoro University. Semarang.

Geertz, C. 1976. The religion of Java. Publisher: University of Chicago Press (online). https://book.google.co Id. Acessted on June 8, 2017.

Ghozali, Imam. 2008. Structural Equation Modeling; Kosep and Applications by Amos Program 16.0. Diponegoro University. Semarang.

Gibson. 1988. Organizational Behavior, Structure, Processes. Erland. Jakarta.

Gibson, James L. John M. Ivancevich, James HD 1996. Organizational Structure and Process Behavior. (Translitor by Nunuk Andriani). Bina Putra. Jakarta.

Kotter, John P. and Heskett, James L. 1992. Corporate Culture and Performance. New York. The Free Press

Maheswaran D. Shavitt, Sharon, 2000. Issues and New Direction in Global Consumcer Psychology. Journal of Consumer Psychology. Ed. 9 (2). p. 59-66

McAllister, Gretchen. Irvine, Jordan. 2000 Cross Cultural Competency and Multicultural Teacher Education, Review of Educational Research Spring. Vol. 70, No. 1, p.3-24.

Mustopadidjaya. 2002. The Public Policy Process Management, Formulation, Implementation and Performance Evaluation, Jakarta.

Ralph Linton and Melville J. Herskovits. 2001. Memorandum for the Study of acculturation. American Anthropologist. V. Riva and Basri AF 2005. Performance Appraisal. PT. King Grafindo Persada. Jakarta.

Robbins, Stephen P. 2006. Organizational Behavior. (Translitor by Benyamin Molan). Tenth Edition. PT. Macanan Jaya Cemerlang. Jakarta.

Sudjana; 2005. Statistical Methods; 6th edition; Publisher Tarsito; Bandung.

Sunyoto, Danang. 2012. Fundamentals of Marketing Management Concepts, Strategies, and Case. Yogyakarta: CAPS.

Williams, Ethlyn A. 2004. Transformational Leadership, Self-Eficacy, Group cohesiveness, Commitment, and Performance. Journal of Organizational Change Management. Vol. 17 Issue: 2 p. 144-159. 